whereas this study was retrospective. In this connection it is impossible to agree that the retrospective nature of the study is advantageous, in that as the authors quote it is likely to record the true state of clinical practice'.

The scientific world rightly demands that any innovation (whether computer-based or not), should be subjected to rigorous evaluation; and the authors are to be warmly commended for their scepticism concerning an important innovation. But it seems only reasonable to suggest that studies of the type outlined by Maitra et al. (1988) should be subjected to the same rigour.

F. T. DE DOMBAL

Clinical Information Science Unit, The University of Leeds,

Leeds, England

\title{
REFERENCE
}

Adam I. D., Chan M., Clifford P. C. et al. (1986) Computer-aided diagnosis of abdominal pain: a multi-centre study. British Medical fournal 293, 800-4.

\section{The use of breath alcohol analysers for diagnosis in the accident and emergency department}

Sir

The use of breath alcohol analysers for diagnosis in the accident and emergency department appears to be well established (Welch et al., 1977; Holt et al., 1980). We are concerned about the lack of evidence for their use in elderly patients.

This department has recently attempted to examine 71 such patients (age range 6597, mean age 76 years) who presented after a fall. Less than half of them (25) were able to activate the automatic sampling device of the Lion SD2 alcolmeter. There was no difference in the mean ages in the group who were able to use the machine and those who were not. In order to obtain the necessary alveolar air, this automatic device traps a sample after the subject has blown at a minimum flow rate of 28 litres per minute for $2.3 \mathrm{~s}$. Thus a minimum of 1.251 of air is discarded. We found that most of our subjects were unable to maintain this flow rate for long enough, which probably reflects their low tidal volume (Fowler, 1985). It may also reflect failure to understand the instructions or simply lack of co-operation.

Whilst we are embarking on a study to examine this more closely we urge your O readers to exercise caution in the interpretation of readings taken from elderly patients using this machine.

G. F. TURNER,* G. WARD \& P. WILSON

Department of Geriatric* and Accident and Emergency Medicine, East Birmingham Hospital, Birmingham, England 


\section{REFERENCES}

Fowler R. W. (1985) Ageing and lung function. Age and Ageing 14, 209-15.

Holt S., Stewart I. C., Dixon J. M. J., Elton R. A., Taylor T. V. \& Little K. (1980) Alcohol and the emergency service patient. British Medical fournal 281, 638-40.

Welch T. P. \& Wright B. M. (1977) Alcohol and road accidents. British Medical fournal i, 1032-4. 